\title{
Guest and Ligand Behavior in Zinc-Seamed Pyrogallol[4]arene Molecular Capsules**
}

\author{
Nicholas P. Power, Scott J. Dalgarno, and Jerry L. Atwood*
}

Molecular capsules have been of significant interest to many for some time as they are not only challenging to assemble with a degree of control, but also because they offer unique chemical environments for molecular material through encapsulation. This confinement of chemical space is still relatively unexplored. ${ }^{[1-8]}$ Among other rigid bowl-shaped molecules, we have been interested in the assembly of the $C$ alkylresorcin[4] arenes and $C$-alkylpyrogallol[4] arenes. ${ }^{[2 a, 9,11]}$ Six $C$-methylresorcin[4]arenes were shown to assemble from aqueous nitrobenzene with eight structural water molecules into a multicomponent hydrogen-bonded nanocapsule encapsulating nitrobenzene. ${ }^{[9]}$ Recently, Ugono and Holman showed that six of these structural water molecules can be substituted with 2-ethylhexanol molecules to form a capsule containing two additional alcohol molecules. ${ }^{[10]}$ The related pyrogallol[4]arenes have been shown to assemble into similar hydrogen-bonded nanocapsules and are also capable of encapsulating various molecular species, as identified in the solid, solution, and gas phases. ${ }^{[1,11-14]}$ In recent times we have used these hydrogen-bonded structures effectively as templates for the (in some cases instantaneous) assembly of large metal-organic analogues by metal insertion into the hydrogen-bonded seam (with concomitant elimination of hydrogen atoms). ${ }^{[15-17]}$ We also recently synthesized an octametalated zinc dimeric capsule based on $C$-propylpyrogallol[4]arene $\left(\mathrm{PgC}_{3}\right)$ that contained a pyridine guest molecule and that also had eight pyridine molecules ligated at the metal centers of the resulting capsule. ${ }^{[18]}$

Herein we show that for the previously reported octametalated zinc dimeric pyrogallol[4]arene capsule motif, ${ }^{[18]}$ it is not only possible to encapsulate the guest molecule of choice (within steric considerations), but it is also possible to perform ligand exchange at the metal periphery with relative ease. In addition, we show that the encapsulation of an asymmetric guest induces a distinct divide between the two hemispheres of the dimeric assembly. Importantly, this asymmetric guest plays a role as a "reporter" for the communication between the ligands and the zinc-seamed capsule; by interchanging ligands and concomitantly varying electron donation to the metal centers, an observed $\mathrm{C}-\mathrm{H} \cdots \pi$

[*] Dr. N. P. Power, Dr. S. J. Dalgarno, Prof. J. L. Atwood

Department of Chemistry

University of Missouri-Columbia

Columbia, MO 65211 (USA)

Fax: (+1) 573-884-9606

E-mail: atwoodj@missouri.edu

$[\cdots \cdots$ This work was supported by the National Science Foundation.

Supporting information for this article is available on the WWWW under http://www.angewandte.org or from the author. interaction of the guest with an arene moiety of the capsule is either enhanced or diminished, thereby translating information between the exterior and interior of the assembly electronically.

Combination of the pentacoordinate zinc(II) complex $\left.\left[\mathrm{Zn}\left(\mathrm{NO}_{3}\right)_{2} \text { (3-methylpyridine }\right)_{3}\right]$ with $\mathrm{PgC}_{3}$ in methanol (Scheme 1) gave instantaneous precipitation of a yellow

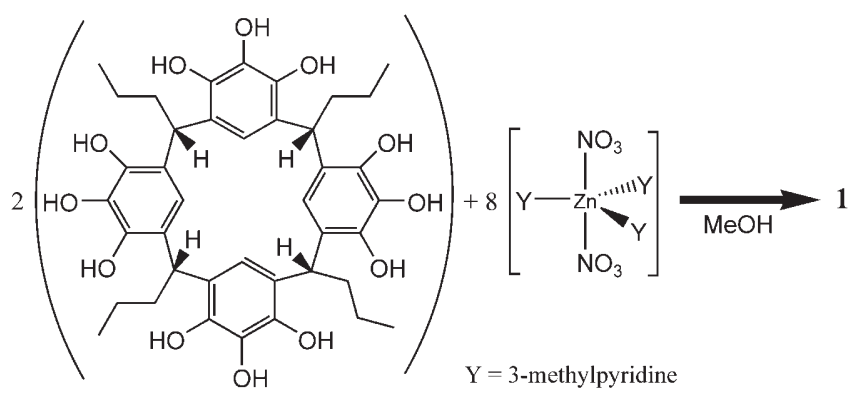

Scheme 1. Formation of $\left[\mathrm{Zn}_{8}(C \text {-propylpyrogallol[4]arene })_{2}\right.$ (3-methylpyridine) ${ }_{8} \subset$ (3-methylpyridine) $]$ (1).

powder that was found to be the complex $\left[\mathrm{Zn}_{8}(C\right.$-propylpyrogallol[4] arene $)_{2}$ (3-methylpyridine $)_{8} \subset(3$-methylpyridine $\left.)\right]$ (1). As it was not possible to crystallize the complex with 3methylpyridine (3-MePy) ligands on the metal centers, we investigated the possibility of removing or rather replacing these ligands with dimethylsulfoxide (DMSO). This was found to proceed with ease either by dialysis in a solution of DMSO in methanol or by repeated azeotropic vacuum distillation with DMSO (boiling points of 3-MePy and DMSO are $144^{\circ} \mathrm{C}$ and $189^{\circ} \mathrm{C}$, respectively) to form the complex $\left[\mathrm{Zn}_{8}(C \text {-propylpyrogallol[4]arene })_{2}(\mathrm{DMSO})_{8} \subset(3-\right.$ methylpyridine)] (2).

Upon allowing a solution of $\mathbf{2}$ in DMSO to stand under a strong direct flow of nitrogen, continued slow evaporation resulted in the growth of large colorless single crystals that were suitable for X-ray diffraction studies. The crystals had triclinic symmetry and the space group $P \overline{1}$. The asymmetric unit contained an entire capsule comprising two $\mathrm{PgC}_{3}$ molecules stitched together by eight zinc centers and shrouding one 3-MePy molecule. In addition, eight DMSO molecules are coordinated to the centers and there are additional noncoordinating DMSO molecules of crystallization. The two bowl-shaped molecules are arranged in a staggered capsule arrangement with respect to metal $\mathrm{PgC}_{3}$ coordination and are equatorially seamed together by eight zinc(II) centers, each of which are coordinated to two phenoxy groups from each $\mathrm{PgC}_{3}$ monomer (Figure 1A). This coordination replaces 16 of the 24 protons available from the aforementioned phenoxy 
A)

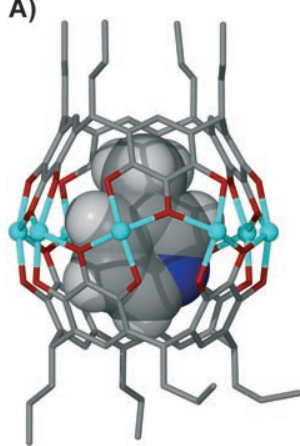

B)

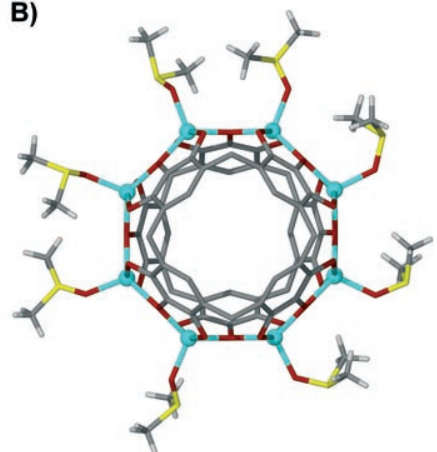

Figure 1. Views of the crystal structure of 2: A) Space-filling representation of encapsulated 3-MePy ( $\mathrm{N}$ dark blue) showing proximity of the guest to the aryl moieties of the $\mathrm{PgC}_{3}$ molecules (DMSO ligands omitted for clarity). B) Stick representation of the DMSO ligands on the metal centers (3-MePy omitted for clarity, S yellow, O red). Zinc centers are shown as light blue balls in both (A) and (B), and selected hydrogen atoms have been omitted in both views for clarity.

groups, leaving 8 protons involved in hydrogen bonding between the ortho-phenoxide units of the $\mathrm{PgC}_{3}$ molecules. The zinc centers are pentacoordinate, and the remaining axial coordination sites are occupied by DMSO ligands coordinating through the oxygen atoms (Figure 1B).

Although both capsules have differences with respect to ligands and guests present, each were identical with respect to $\mathrm{Zn}-\mathrm{O}$ bond lengths and $\mathrm{O}-\mathrm{Zn}-\mathrm{O}$ angles. However, for the capsule analogue in which pyridine is encapsulated and pyridine ligands are present on the zinc centers, the guest was poorly resolved owing to molecular rotation. ${ }^{[18]}$ In the present case, the methyl group on the pyridine ring prevents such rotation, and the molecule is well-resolved on the capsule interior (Figure 1A). The methyl group of 3-MePy is clearly positioned in close proximity to the arene moiety of the dimer, and there is significant $\mathrm{C}-\mathrm{H} \cdots \pi$ interaction between host and guest. The calculated space encapsulated in the crystal structure of $\mathbf{2}$ is approximately $143 \AA^{3}$ (measured with a test radius of $1.25 \AA$ ), which is comparable to the value of $141 \AA^{3}$ for the previously reported encapsulation of pyridine. ${ }^{[19]}$

Detailed NMR studies reveal interesting electronic communication between the host and the guest ${ }^{[20]}$ through influence by the interchangeable ligands on the metal centers. As one would expect (from literature studies), the proton shifts for encapsulated 3-MePy experience considerable upfield displacement relative to those for the free molecule. ${ }^{[21]}$ The recorded $\Delta \delta$ values (Table 1 ) for the methyl group of the encapsulated 3-MePy molecule were greater than $4 \mathrm{ppm}$, which is correlated by the crystal structure (and indicated to some extent in Figure $1 \mathrm{~A}$ ). The $\Delta \delta$ values for the remaining aromatic protons of the encapsulated 3-MePy guest are also large (Table 1), but are reflective of their equatorial proximity to other aryl moieties of the dimeric capsule (Figure 1A). Similar values have been noted by Chapman and Sherman for close proton proximity and equatorial positioning of guests to the arene moiety in carceplexes. ${ }^{[21]}$

At this point, it is appropriate to describe the dual hemispherical nature of the dimeric capsule as north and

Table 1: Chemical shifts of 3-MePy as a free molecule and bound in the octametalated zinc dimeric capsule with either DMSO or 3-MePy ligands on the metal centers.

\begin{tabular}{llllllr}
\hline Ligand & 3-MePy & $\begin{array}{l}\delta_{\mathrm{H}_{\mathrm{a}}} \\
{[\mathrm{ppm}]}\end{array}$ & $\begin{array}{l}\delta_{\mathrm{H}_{\mathrm{b}}} \\
{[\mathrm{ppm}]}\end{array}$ & $\begin{array}{l}\delta_{\mathrm{H}_{c}} \\
{[\mathrm{ppm}]}\end{array}$ & $\begin{array}{l}\delta_{\mathrm{H}_{\mathrm{d}}} \\
{[\mathrm{ppm}]}\end{array}$ & $\begin{array}{r}\delta_{\mathrm{Me}} \\
{[\mathrm{ppm}]}\end{array}$ \\
\hline \multirow{3}{*}{ DMSO } & free & 8.41 & 7.53 & 7.22 & 8.38 & 2.29 \\
& guest & 5.57 & 4.59 & 4.36 & 5.33 & -2.21 \\
& $\Delta \delta^{[\mathrm{a}]}$ & 2.84 & 2.94 & 2.86 & 3.05 & 4.50 \\
& & & & & & -1.79 \\
3-MePy & guest & 6.13 & 4.94 & 4.84 & 5.87 & 4.08 \\
& $\Delta \delta^{[\mathrm{a}]}$ & 2.28 & 2.59 & 2.38 & 2.51 & 0.42 \\
& & & & & & \\
& $\Delta \Delta \delta^{[\mathrm{b}]}$ & 0.56 & 0.35 & 0.48 & 0.54 & \\
\hline
\end{tabular}

[a] $\Delta \delta=\delta_{\text {free }}-\delta_{\text {guest }} ;[\mathrm{b}] \Delta \Delta \delta=\delta_{\text {DMSO }}-\delta_{3-\mathrm{MePy}}$

south relative to what can be termed a zinc equator (Scheme 2). The equatorial divide is exaggerated by the encapsulation of the asymmetric 3-MePy guest. Its introduction enforces two different chemical environments within the capsule, a distinctive north-south divide, whereby the hemisphere occupied by the guest's methyl group is for our purposes assigned as north. The difference in these chemical environments is clearly expressed in both the ${ }^{1} \mathrm{H}$ and ${ }^{13} \mathrm{C}$ NMR spectra. The ${ }^{1} \mathrm{H}$ NMR spectrum shows splitting of signals for the hydrogen-bonded protons of the capsule $\quad(\delta=17.61 \quad$ and $17.34 \mathrm{ppm}$, which also experience significant deshielding by the presence of the oxygenbonded metals), aryl protons $(\delta=6.58$ and $6.28 \mathrm{ppm})$, to a

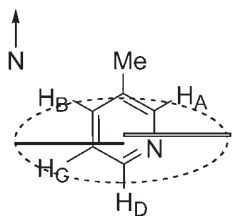

Scheme 2. Representation of the imposed dual-hemispherical nature of the assembly as a result of the encapsulation of the asymmetric guest 3-methylpyridine. For the purpose of describing interactions within the capsule, we have assigned direction ( $\mathrm{N}$ : north) to the scheme of the assembly; the superimposed horizontal bars indicate the north-south divide.

ylene protons (broad peak at $\delta=4.19 \mathrm{ppm}$ ), and even the protons of the first methylene of the $C$-propyl chain $(\delta=2.22$ and $2.12 \mathrm{ppm}$ ) (see the Supporting Information for spectra).

By exchanging the heterocyclic ligands with a lesselectron-donating species (DMSO), the electropositive metal centers need to supplement for the loss of electron density. This is done by drawing density from the aryl rings, a feature that of course has significant effects on the host-guest interactions, which are readily catalogued by NMR analysis. With this change in electronic distribution, guest mobility is affected and inevitably influences the $\mathrm{C}-\mathrm{H} \cdots \pi$ interactions of the guest. This result was aptly demonstrated by NMR titration of the heterocyclic ligand to a solution of the zincseamed dimeric capsule in deuterated DMSO (Figure 2). By increasing the titer of 3-MePy and by concomitant replacement of DMSO as the ligands for the zinc centers, the guest peaks continue to shift downfield, a consequence of the changing $\pi$-electron density throughout the aryl moiety. The titration was continued to saturation, where competitive exchange with DMSO was dominated by the weak hetero- 


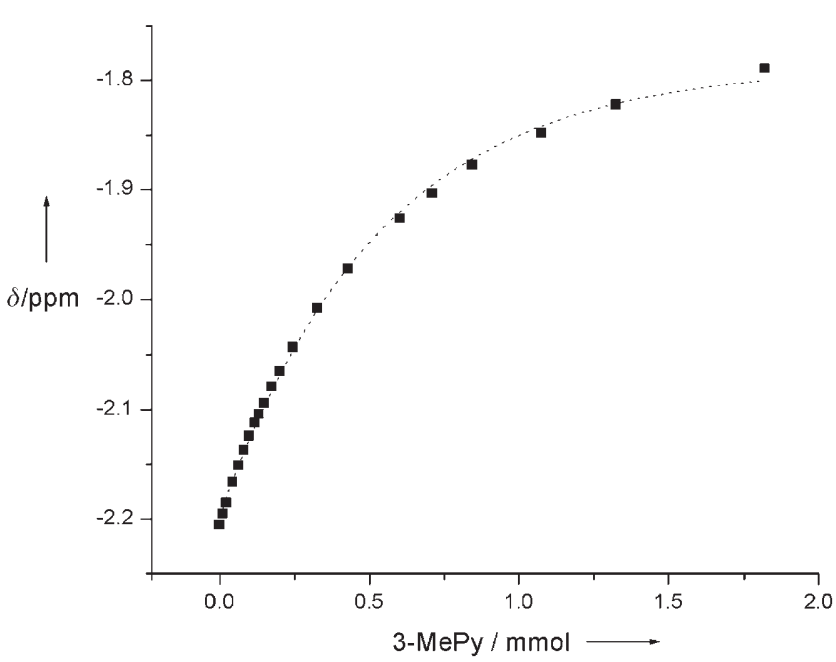

Figure 2. Titration plot of ligand (3-MePy) into a solution of $\mathbf{2}$ in $\left[D_{6}\right]$ DMSO for the methyl shift of the 3-MePy guest. Ligand concentration in solution was calculated relative to the capsule concentration by integration of the NMR signals. Note the increase in $\delta$ owing to the ligand exchange of DMSO with the electron-donating 3-MePy ligand on the zinc centers.

cyclic ligand for coordination with the octametalated dimer. Saturation, thus, implies complete coordination by 3-methylpyridine in the solution phase. The weakening of the $\mathrm{C}-\mathrm{H} \cdots \pi$ interactions is reflected by the values of $\Delta \Delta \delta$ (Table 1 ). This redistribution of electron density was also noted to affect the chemical shifts for the respective hemispheres to a lesser but still significant extent (see the Supporting Information).

In conclusion, we have demonstrated the facile and selective guest placement within a dimeric metalated capsule, as well as interchangeable ligand exchange on the metal centers that seam the capsule assembly together. The latter features is particularly important for the use of these robust frameworks in coordination network formation. The use of ligand properties to translate electronically to the guest on the capsule interior gives valuable insight into the properties of a "tight chemical space for encapsulation" and is a useful tool for studying such interactions through space. Work continues into the encapsulation of other species and the possible formation of larger assemblies based on this building block.

\section{Experimental Section}

NMR spectra were acquired on a Bruker AXR500 NMR spectrometer $(500 \mathrm{MHz})$. For dialysis, Spectra/Por 6 Dialysis Membranes with a molecular weight cutoff of $1000 \mathrm{Da}$ were used. Synthesis of $C$ propylpyrogallol[4]arene was according to a literature procedure. ${ }^{[22]}$

$\left[\mathrm{Zn}_{8}(C \text {-propylpyrogallol[4]arene })_{2}(3 \text {-methylpyridine })_{8} \subset(3\right.$-methylpyridine $)](\mathbf{1})$ : A solution of $\left.\left[\mathrm{Zn}^{\mathrm{II}}\left(\mathrm{NO}_{3}\right)_{2} \text { (3-methylpyridine }\right)_{3}\right](1.0 \mathrm{~g}$, $2.13 \mathrm{mmol})$ in $\mathrm{MeOH}(5 \mathrm{~mL})$ was mixed with a solution of $C$ propylpyrogallol[4]arene $(0.374 \mathrm{~g}, 0.519 \mathrm{mmol})$ in $\mathrm{MeOH}(16 \mathrm{~mL})$ in an open container. Instantaneous precipitation of a yellow solid was observed and the mixture was briefly sonicated to ensure completion of reaction. The yellow precipitate was filtered and dried under vacuum. Yield: $0.642 \mathrm{~g}, 98 \% .{ }^{1} \mathrm{H}$ NMR $\left(500 \mathrm{MHz},\left[\mathrm{D}_{6}\right] \mathrm{DMSO}\right.$, shifts are relative to residual protio DMSO): $\delta=17.69(4 \mathrm{H}), 17.43(4 \mathrm{H})$, $8.41(16 \mathrm{H}, \mathrm{m}$, ligand $), 7.72(8 \mathrm{H}, \mathrm{m}$, ligand $), 7.39(8 \mathrm{H}, \mathrm{m}$, ligand $), 6.63$
$(4 \mathrm{H}, \mathrm{m}), 6.34(4 \mathrm{H}, \mathrm{m}), 5.72(1 \mathrm{H}, \mathrm{m}, \subset 3-\mathrm{MePy}), 5.48(1 \mathrm{H}, \mathrm{m}, \subset 3-$ MePy), $4.68(1 \mathrm{H}, \mathrm{m}, \subset 3-\mathrm{MePy}), 4.49(1 \mathrm{H}, \mathrm{m}, \subset 3-\mathrm{MePy}), 4.24(8 \mathrm{H}$, $\mathrm{m}), 2.31(24 \mathrm{H}, \mathrm{s}$, ligand $), 2.26$ and $2.15(16 \mathrm{H}, 2 \times \mathrm{s}), 1.37(16 \mathrm{H}, \mathrm{brs})$, $0.98(24 \mathrm{H}, \mathrm{t}),-2.02$ and $-2.09 \mathrm{ppm}(3 \mathrm{H} 2 \times \mathrm{s}) ;{ }^{13} \mathrm{C}$ NMR: $\delta=149.39$ (ligand), 146.50 (ligand), 142.43, 142.10, 141.40 ( $\subset 3-M e P y), ~ 140.04$, 139.36 137.78, 133.79, 132.62 ( $\subset 3$-MePy), 131.47 ( $\subset 3$-MePy), 124.19 and $123.83,123.96$ (ligand), 122.41 ( $\subset 3-\mathrm{MePy}), 108.72$ and 108.15 (Ar$\mathrm{H}), 35.45$ and $35.38(\mathrm{CH}), 32.15,21.07,17.95,14.20$ and $14.15(\mathrm{Me})$, $12.20 \mathrm{ppm}(\subset 3-\mathrm{MePy})$.

$\left[\mathrm{Zn}_{8}(C \text {-propylpyrogallol[4] }] \text { arene }\right)_{2}(\mathrm{DMSO})_{8} \subset(3$-methylpyridine)] (2): A solution of $\mathbf{1}$ in MeOH/DMSO (9:1) was prepared in a dialysis bag (ca. $4 \mathrm{mg} \mathrm{mL}^{-1}$ ) and dialyzed against two consecutive batches of MeOH/DMSO solvent mixtures in a 10-fold volume excess to the bagged solution in a beaker and allowed to stir for $4 \mathrm{~h}$ or more in each case. The solvent was removed by high vacuum rotary evaporation. For NMR purposes we replaced the DMSO ligands with $\left[\mathrm{D}_{6}\right] \mathrm{DMSO}$ by using repeated azeotropic vacuum distillation. Recovery of the newly DMSO-ligated product 2 by dialysis was up to $70 \%$. ${ }^{1} \mathrm{H}$ NMR $\left(500 \mathrm{MHz},\left[\mathrm{D}_{6}\right] \mathrm{DMSO}\right.$, shifts are relative to residual protio DMSO): $\delta=17.61(4 \mathrm{H}), 17.34(4 \mathrm{H}), 7.49(1 \mathrm{H}, \mathrm{s}), 6.58(4 \mathrm{H}, \mathrm{m}), 6.28$ $(4 \mathrm{H}, \mathrm{m}), 5.56(1 \mathrm{H}, \mathrm{m}, \subset 3-\mathrm{MePy}), 5.32(1 \mathrm{H}, \mathrm{m},(\subset 3-\mathrm{MePy}), 4.59(1 \mathrm{H}$, $\mathrm{m}, \subset 3-\mathrm{MePy}), 4.35(1 \mathrm{H}, \mathrm{m}, \subset 3-\mathrm{MePy}), 4.19(8 \mathrm{H}, \mathrm{m}), 2.22$ and 2.12 $(16 \mathrm{H}, 2 \times \mathrm{s}), 1.26(16 \mathrm{H}, \mathrm{brs}), 0.97(24 \mathrm{H}, \mathrm{t}),-2.12$ and $-2.21 \mathrm{ppm}$ $(3 \mathrm{H}, 2 \times \mathrm{s}, \subset 3-\mathrm{MePy}) ;{ }^{13} \mathrm{C}$ NMR: $\delta=143.26$ and $142.92,142.26$ ( $\subset 3-$ MePy), 140.83 and 140.15, 133.47 ( $\subset 3-\mathrm{MePy}), 132.33$ ( $\subset 3-\mathrm{MePy}$ ), 125.06 and $124.70,123.26$ ( $\subset 3-\mathrm{MePy}), 109.52$ and 108.94, 36.30, 33.10, $22.02,15.16$ and $15.10,15.07 \mathrm{ppm}(\subset 3-\mathrm{MePy})$.

Data for 2 were collected on a Bruker SMART 1000 CCD diffractometer, CCDC 652121 contains the supplementary crystallographic data for this paper. These data can be obtained free of charge from The Cambridge Crystallographic Data Centre via www.ccdc. cam.ac.uk/data_request/cif. Crystal data: $\mathrm{C}_{102} \mathrm{H}_{135} \mathrm{~N}_{1} \mathrm{O}_{32} \mathrm{~S}_{8} \mathrm{Zn}_{8}, M_{\mathrm{r}}=$ $2666.55,0.45 \times 0.6 \times 0.6 \mathrm{~mm}^{3}$, triclinic, $a=15.064(6), b=15.316(6)$, $c=29.238(12) \AA, \alpha=101.340(8), \beta=96.857(8), \gamma=91.826(8)^{\circ}, V=$ $6556(5) \AA^{3}, \quad$ space group $P \overline{1}, \quad Z=2, \quad \rho_{\text {calcd }}=1.351, \quad \lambda\left(\mathrm{Mo}_{\mathrm{K} \alpha}\right)=$ $0.71073 \AA, T=173(2) \mathrm{K}, 46753$ reflections, 28186 unique (15052 observed, $\left.R_{\text {int }}=0.0370\right), R_{1}=0.0707, \omega R_{2}($ all data $)=0.1985$ for 1405 parameters and 23 restraints. The routine SQUEEZE was applied to the data to remove diffuse electron density associated with disordered noncoordinating DMSO solvents of crystallization.

MALDI-TOF MS analysis: Spectra were collected on a Voyager DE-PRO instrument. Crystals were dissolved and cocrystallized in a dithranol matrix $\left(10 \mathrm{mg} \mathrm{mL}^{-1}\right.$ in $\left.\mathrm{CHCl}_{3}\right)$. All analyses were conducted on a gold MALDI plate. The Voyager DE-PRO instrument was operated in a reflector positive-ion mode $(20 \mathrm{kV}$ acceleration, $150 \mathrm{~ns}$ delayed extraction, 600 to 4000 mass range). Spectra were acquired at a laser intensity of 1200 , and 500 spectra per acquisition were accumulated to a total of 2000 spectra by moving the laser around the spot. A $[M+\mathrm{H}]^{+}$ion at $2041 \mathrm{Da}$ was obtained for $\left[\mathrm{Zn}_{8}(C\right.$-propylpyrogallol[4]arene $)_{2} \subset(3$-methylpyridine)] stripped of its ligands in the gas phase, which is in good agreement with calculated values.

Received: July 3, 2007

Revised: August 17, 2007

Published online: September 20, 2007

Keywords: coordination modes - inclusion compounds . molecular capsules · self-assembly · supramolecular chemistry

[1] S. J. Dalgarno, S. A. Tucker, D. B. Bassil, J. L. Atwood, Science 2005, 309, 2037-2039.

[2] a) G. W. V. Cave, J. Antesberger, L. J. Barbour, R. M. McKinlay, J. L. Atwood, Angew. Chem. 2004, 116, 5375-5378; Angew. Chem. Int. Ed. 2004, 43, 5263-5266; b) A. Shivanyuk, J. Rebek, Jr., J. Am. Chem. Soc. 2003, 125, $3432-3433$. 
[3] J. L. Atwood, L. J. Barbour, A. Jerga, Proc. Natl. Acad. Sci. USA 2002, 99, 4837-4841.

[4] G. W. Orr, L. J. Barbour, J. L. Atwood, Science 1999, 285, 1049 1052.

[5] J. L. Atwood, L. J. Barbour, S. J. Dalgarno, M. J. Hardie, C. L. Raston, H. R. Webb, J. Am. Chem. Soc. 2004, 126, 13170-13171; J. L. Atwood, K. T. Holman, J. W. Steed, Chem. Commun. 1996, 1401-1407.

[6] T. Heinz, D. M. Rudkevich, J. Rebek, Jr., Nature 1998, 394, 764 766; J. Kang, J. Rebek, Jr., Nature 1996, 382, 239-241.

[7] J. C. Sherman, D. J. Cram, J. Am. Chem. Soc. 1989, 111, $4527-$ 4529.

[8] H. Mansikkamäki, M. Nissinen, K. Rissanen, Chem. Commun 2002, $1902-1903$

[9] L. R. MacGillivray, J. L. Atwood, Nature 1997, 389, 469-472.

[10] O. Ugono, K. T. Holman, Chem. Commun. 2006, 2144-2146.

[11] a) S. J. Dalgarno, N. P. Power, J. Antesberger, R. M. McKinlay, J. L. Atwood, Chem. Commun. 2006, 3803-3805; b) J. L. Atwood, L. J. Barbour, A. Jerga, Chem. Commun. 2001, $2376-$ 2377; c) J. L. Atwood, L. J. Barbour, A. Jerga, J. Supramol. Chem. 2001, 1, 131-134.

[12] a) E. S. Barrett, T. J. Dale, J. Rebek, Jr., J. Am. Chem. Soc. 2007, 129, 3818-3819; b) T. Gerkensmeier, W. Iwanek, C. Agena, R. Froehlich, S. Kotila, C. Nather, J. Mattay, Eur. J. Org. Chem. 1999, 2257-2262.

[13] a) D. B. Bassil, S. J. Dalgarno, G. W. V. Cave, J. L. Atwood, S. A. Tucker, J. Phys. Chem. B, 2007, 11, 9088-9092; b) S. J. Dalgarno,
D. B. Bassil, S. A. Tucker, J. L. Atwood, Angew. Chem. 2006, 118, 7177-7180; Angew. Chem. Int. Ed. 2006, 45, 7019-7022.

[14] N. K. Beyeh, M. Kogej, A. Aahman, K. Rissanen, C. A. Schalley, Angew. Chem. 2006, 118, 5339-5342; Angew. Chem. Int. Ed. 2006, 45, 5214-5218.

[15] S. J. Dalgarno, N. P. Power, J. E. Warren, J. L. Atwood, unpublished results.

[16] R. M. McKinlay, P. K. Thallapally, G. W. V. Cave, J. L. Atwood, Angew. Chem. 2005, 117, 5879-5882; Angew. Chem. Int. Ed. 2005, 44, 5733-5736.

[17] R. M. McKinlay, G. W. V. Cave, J. L. Atwood, Proc. Natl. Acad. Sci. USA 2005, 102, 5944-5948.

[18] N. P. Power, S. J. Dalgarno, J. L. Atwood, New J. Chem. 2007, 31, $17-20$.

[19] L. J. Barbour, 2003 MCAVITY, program for calculating the molecular volume of closed capsules, University of MissouriColumbia, Columbia, MO, USA. http://www.x-seed.net/cavity. html. Maximum free volume within the cavities was calculated in absence of guest.

[20] There is a peak in the ${ }^{1} \mathrm{H}$ NMR spectrum that may be attributed to protonation of the guest $(\delta=7.49$ and $7.61 \mathrm{ppm}$ for the DMSO- and 3-MePy-ligated capsules, respectively); see the Supporting Information.

[21] R. G. Chapman, J. C. Sherman, J. Org. Chem. 2000, 65, 513-516.

[22] F. Weinelt, H. J. Schneider, J. Org. Chem. 1991, 56, 5527-5535. 